\title{
Dietary pattern and weight change in a 5-year follow-up among Chinese adults: results from the Jiangsu Nutrition Study
}

\author{
Zumin Shi ${ }^{1,2 *}$, Baojun Yuan ${ }^{1}$, Gang $\mathrm{Hu}^{3}$, Yue Dai ${ }^{1}$, Hui Zuo ${ }^{1}$ and Gerd Holmboe-Ottesen ${ }^{2}$ \\ ${ }^{1}$ Nutrition and Foodborne Disease Prevention, Jiangsu Provincial Center for Disease Control and Prevention, \\ 172 Jiangsu Road, Nanjing 210009, China \\ ${ }^{2}$ Department of General Practice and Community Medicine, University of Oslo, Oslo, Norway \\ ${ }^{3}$ Pennington Biomedical Research Center, Louisiana State University System, Baton Rouge, LA, USA \\ (Received 16 March 2010 - Revised 5 October 2010 - Accepted 14 October 2010 - First published online 25 November 2010)
}

\section{Abstract}

The aim of the present study was to examine the association between dietary patterns and weight change prospectively. We followed up 1231 adults aged 20 years and older (mean age 49.3 years) from 2002 to 2007. Food intake was assessed at baseline by an FFQ. Factor analysis was used to identify dietary patterns. Nutrient intake was measured by food weighing plus consecutive individual $3 \mathrm{~d}$ food records Body weight and height were measured. The mean 5-year weight gain among all participants was 0.8 (SD 4.7 ) kg. The mean weight changes across quartiles of the 'traditional' pattern (rice, fresh vegetables, pork and wheat flour) were $2 \cdot 0,0 \cdot 6,0 \cdot 6$ and $0 \cdot 0 \mathrm{~kg}$. The corresponding values were $0.4,0.5,0.7$ and $1.6 \mathrm{~kg}$ across quartiles of the 'vegetable-rich' pattern. No significant association between the 'macho' dietary pattern (meat and alcohol), the 'sweet tooth' pattern (drinks and cake) and weight gain was found. In multivariate linear regression, using the first quartile as the reference, participants in the highest quartile of the 'traditional' pattern had a $\beta$ of $-2 \cdot 18$ ( $95 \% \mathrm{CI}-2 \cdot 91$, -1.45 ) for weight gain. However, the $\beta$ from weight change of the highest quartile of the 'vegetable-rich' pattern was 1.00 ( $95 \% \mathrm{CI}$ $0 \cdot 25,1 \cdot 74)$. In conclusion, the 'traditional' dietary pattern was negatively and the 'vegetable-rich' pattern was positively associated with weight gain in Chinese adults.

\section{Key words: Dietary patterns: Weight change: Obesity: Adults: China}

Obesity is a major health problem worldwide ${ }^{(1)}$. Much attention has been drawn to the obesity epidemic because of the high economic burden as well as its association with many non-communicable chronic diseases including diabetes, CHD and cancer. Physical activity and diet are two key determinants of obesity ${ }^{(2)}$.

Extensive research has been done on the association between a single food or nutrient and obesity ${ }^{(2,3)}$. As foods or nutrients may interact, knowledge on single foods or nutrients in association with weight change has limited value ${ }^{(4)}$. Comprehensive analyses (e.g. Healthy Eating Index) and use of dietary patterns have become popular approaches ${ }^{(4)}$. Dietary patterns derived by factor analysis have been found to be associated with weight gain in Western countries ${ }^{(5-7)}$. A dietary pattern rich in fruits and vegetables has consistently been negatively associated with weight gain, while a Western dietary pattern has been positively associated with weight gain $^{(5-7)}$. Cross-sectional studies from East Asian countries have shown an association between dietary pattern and overweight/obesity $^{(8-10)}$. However, to establish a causal link between diet and overweight, longitudinal studies are needed. Nevertheless, longitudinal studies on the association between the traditional Chinese dietary pattern and weight gain are limited. As food culture and cooking methods are different between the Eastern and Western worlds ${ }^{(10)}$, it is of importance to have a clear understanding of this association in the Eastern world.

Randomised control trials show the benefit of a lowcarbohydrate, a low-fat or a Mediterranean diet, and weight $\operatorname{loss}^{(11,12)}$. Because of its benefits in regard to obesity and CVD prevention, the Mediterranean diet has attracted wider attention.

The traditional Chinese diet has many similarities with the Mediterranean diet (high intake of vegetables, grains, legumes and high MUFA:SFA ratio), with the exception of a low intake of dairy products and wine ${ }^{(13)}$. A study from China showed that a high percentage of energy intake from cereals was significantly associated with lower $\mathrm{BMI}^{(14)}$. We previously reported the associations between 
dietary patterns and obesity among Chinese adults in a cross-sectional study. We found a positive association between the vegetable-rich pattern and obesity, while no association was found between the traditional pattern and obesity ${ }^{(10)}$. Due to the limitation of the cross-sectional design, we could not conclude a causal relationship. Using the same sample, the present study investigates 5-year weight change according to dietary pattern at baseline derived by factor analysis among Chinese adults.

\section{Research design and methods}

\section{Sample}

The Jiangsu Nutrition Study is an ongoing cohort study investigating the association of nutrition and other factors with the risk of non-communicable chronic disease. The sample was based on a subsample of the Chinese National Nutrition and Health Survey representing Jiangsu Province, and the year 2002 was used as a baseline. The rural sample was selected from six counties (Jiangyin, Taichang, Shuining, Jurong, Sihong and Haimen). From each of the six counties, three smaller towns were randomly selected. The urban sample was selected from the capital cities of two prefectures, Nanjing and Xuzhou; and from each capital city, three streets were randomly selected. The six counties and the two prefectures represented a geographically and economically diverse population. In each town/street, two villages/ neighbourhoods were randomly selected, and ninety households were further selected randomly from each village/neighbourhood. All the members in the households were invited to take part in the study. In addition, one-third of the households were interviewed on dietary intake. Written consents were obtained from all the participants. The present study was conducted according to the guidelines laid down in the Declaration of Helsinki, and all procedures involving human subjects were approved by the Jiangsu Provincial Center for Disease Control and Prevention.

In 2002, 2849 adults aged 20 years and above provided dietary information. In 2007, only 1682 participants could be identified; of these, 1492 participated in the study, and of these, 1282 participants' height and weight were measured. The rest of the participants had either migrated to other cities for temporary work or moved out of the original streets to other streets within the urban area. For the present analysis, we excluded those participants who had extreme values of weight change more than $20 \mathrm{~kg}$ ( $n$ 11) and those who had known diabetes, stroke or cancer at baseline ( $n$ 40). The final sample in the study consisted of 510 men and 721 women. Compared with the retained participants, those lost to follow-up were generally younger ( $45.5 v .49 .3$ years). No differences in mean BMI and energy intake were found.

\section{Data collection and measurements}

Participants were interviewed at their homes by health workers using a standard questionnaire. All health workers were intensively trained in meeting and in practical sessions.

\section{Outcome variables (height and weight)}

Height and weight were measured both at baseline and at the follow-up. At each study site, health workers measured height and weight according to the standard protocols. Weight was measured without shoes and light indoor clothing to the nearest $0.1 \mathrm{~kg}$ by using a beam balance scale. Height was measured to the nearest $0 \cdot 1 \mathrm{~cm}$ by using a stadiometer. BMI was calculated as weight in $\mathrm{kg}$ divided by the square of the height in $\mathrm{m}$.

\section{Independent variables (dietary measurements)}

Diet during the past year was investigated at baseline by an FFQ with detailed questions about the usual frequency and quantity of intake of thirty-three food groups and beverages $^{(10)}$. The list of foods was further collapsed into twenty-five main food groups in the analysis because of the low intake of some items. Portion size for each food was established by reference to food models. Subjects were asked to recall the frequency of consumption of individual food items (number of times/d, number of times/ week, number of times/month and number of times/ year) and the estimated portion size using local weight units (liang $(50 \mathrm{~g})$ ) or natural units (cups). Intakes of foods were converted into local weight units (liang) or natural units (cups, for beer and beverages) per $\mathrm{d}$ and were used in further analysis. These food intake variables were standardised (mean 0 (SD 1)) before performing the factor analysis.

The FFQ was validated ${ }^{(15,16)}$ and reported to be a useful method for the collection of individual food consumption information in face-to-face interviews, but not in self-administered surveys due to the current educational level of the majority of the Chinese population.

Dietary patterns (main independent variables) were identified by factor analysis using the standard principal component analysis method. Factors were rotated with an orthogonal (varimax) rotation to improve interpretability and minimise the correlation between the factors. The number of factors retained from each food classification method was determined by eigenvalue $(>1)$, scree plot, factor interpretability and the variance explained $(>5 \%)$ by each factor. Labelling of the factors was primarily descriptive and based on our interpretation of the pattern structures.

Factor analysis was done using Chinese servings/d as input variables. Factor loadings are equivalent to simple correlation between the food items and the factor. 
Higher loadings (absolute value) indicate that the food shares more variance with that factor. The sign of the loading determines the direction of the relationship of each food with the factor. Food groups with absolute values $<0 \cdot 20$ are not presented for simplicity.

Participants were assigned pattern-specific factor scores. Scores for each pattern were calculated as the sum of the products of the factor loading coefficients and standardised weekly intake of each food associated with that pattern.

Nutrient and vegetable oil intakes were measured at baseline both by food weighing and by consecutive individual $3 \mathrm{~d}$ food records. We did not consider underand over-reporting of energy intake as an issue of concern because any unreliable data were checked by the health workers during the survey. Food consumption data were analysed using the Chinese Food Composition Table ${ }^{(17)}$.

\section{Covariates}

Smoking and drinking. Cigarette smoking was assessed by asking the participants about the frequency of daily cigarette smoking. Alcohol consumption was assessed by asking the participants about the frequency and amount of alcohol/beer intake.

Physical activity and inactivity. Information on physical activity was collected using a validated physical activity questionnaire covering a time period of 1 year ${ }^{(18)}$. Questions on daily commuting to and from work were categorised into three categories: (1) using motorised transportation or not ( 0 min of walking or cycling); (2) walking or bicycling 1-29 min; (3) walking or bicycling for $\geq 30 \mathrm{~min}$. Daily leisure-time physical activity was classified into three categories: 0; 1-29; $\geq 30 \mathrm{~min}$.

Socio-economic status. Education was recoded into three categories based on six categories of educational levels in the questionnaire: 'low': illiteracy, primary school; 'medium': junior middle school; 'high': high middle school or higher. Occupation was recoded into manual or non-manual based on a question with twelve occupational categories.

\section{Statistical analyses}

Factor scores were divided into quartiles, implying increased intake from quartile 1 to quartile 4 . The $\chi^{2}$ test was used to compare the difference between categorical variables. Multivariate linear regression was used to determine the association between dietary pattern and weight change. Three stepwise models were used: model 1 adjusted for age and sex; model 2 further adjusted for education, occupation, active commuting, leisure-time physical activity, smoking and alcohol drinking; model 3 further adjusted for energy intake. Factor analysis was performed using SPSS 11.0 (SPSS, Inc., Chicago, IL, USA). All the other analyses were performed using STATA 10 (Stata Corporation, College Station, TX, USA). Statistical significance was considered when $P<0.05$ (two-sided).

\section{Results}

Four dietary patterns were obtained by factor analysis. Factor loadings for the four dietary patterns are presented in Table 1. Factor 1 ('macho') was characterised by various kinds of animal foods and alcohol, i.e. foods commonly eaten by men. The 'traditional' pattern (factor 2) loaded heavily on rice and fresh vegetables and inversely on wheat flour. Factor 3 ('sweet tooth') contained cake, milk, yogurt and drinks, and more women than men could be associated with this pattern. Factor 4 ('vegetablerich' pattern) included whole grains, fruits, root vegetables, fresh and pickled vegetables, milk, eggs and fish. The four factors explained $28.5 \%$ of the variance in intake $(9.8,8.0$, 5.5 and $5 \cdot 2 \%$ for factor 1 to factor 4 , respectively).

Table 1. Factor loadings for the four dietary patterns among adults in Jiangsu, China

\begin{tabular}{|c|c|c|c|c|c|c|c|}
\hline \multicolumn{2}{|c|}{ Factor 1: 'macho' } & \multicolumn{2}{|c|}{ Factor 2: 'traditional' } & \multicolumn{2}{|c|}{ Factor 3: 'sweet tooth' } & \multicolumn{2}{|c|}{ Factor 4: 'vegetable-rich' } \\
\hline $\begin{array}{l}\text { Food or } \\
\text { food group }\end{array}$ & $\begin{array}{l}\text { Factor } \\
\text { loadings }\end{array}$ & $\begin{array}{l}\text { Food or } \\
\text { food group }\end{array}$ & $\begin{array}{l}\text { Factor } \\
\text { loadings }\end{array}$ & $\begin{array}{l}\text { Food or } \\
\text { food group }\end{array}$ & $\begin{array}{l}\text { Factor } \\
\text { loadings }\end{array}$ & $\begin{array}{l}\text { Food or } \\
\text { food group }\end{array}$ & $\begin{array}{l}\text { Factor } \\
\text { loadings }\end{array}$ \\
\hline Poultry & 0.55 & Rice & 0.78 & Cake & 0.59 & Whole grains & 0.56 \\
\hline Beer & 0.54 & Fresh vegetables & 0.61 & Juice & 0.57 & Fruits & 0.47 \\
\hline Alcohol & 0.50 & Pork & 0.38 & Beverages* & 0.48 & Tofu & 0.48 \\
\hline Beef, lamb & 0.45 & Fish & 0.24 & Milk & 0.47 & Pickled vegetables & 0.42 \\
\hline Deep-fried products & 0.45 & Pickled vegetables & 0.20 & Yogurt & 0.43 & Root vegetables & 0.36 \\
\hline Pork & 0.43 & Root vegetables & -0.28 & Beef, lamb & 0.30 & Wheat flour & 0.32 \\
\hline Liver & 0.43 & Wheat flourt & -0.75 & Nuts & 0.26 & Milk & 0.31 \\
\hline Eggs & 0.37 & & & Poultry & 0.25 & Fresh vegetables & 0.29 \\
\hline Fish & 0.26 & & & Fruits & 0.22 & Eggs & 0.30 \\
\hline Nuts & 0.24 & & & Pickled vegetables & -0.22 & Milk powder & 0.23 \\
\hline Fruits & 0.24 & & & Alcohol & -0.31 & Fish & 0.22 \\
\hline Tofu & 0.21 & & & & & Rice & -0.26 \\
\hline & & & & & & Beer & -0.22 \\
\hline Variance explained (\%) & 9.8 & & 8.0 & & 5.5 & & $5 \cdot 2$ \\
\hline
\end{tabular}

* Beverages include soft drinks, coffee and tea.

† Wheat flour includes noodles and steamed dumplings. 
There were significant differences in the intake of fruits, vegetables, rice, wheat flour, whole grains, pork and fish across quartiles of the 'traditional' dietary pattern (Table 2). Education was positively associated with this pattern. A clear increasing trend of the intake of fat was seen across quartiles of the 'traditional' pattern from low to high. Participants in the first quartile of this pattern had the highest intake of wheat flour and dietary fibre compared with the other groups. However, no significant difference was found in the intake of vegetable oil across quartiles of this pattern. There was a significant negative association between the 'traditional' pattern and energy density.

The food and nutrient intakes across quartiles of the 'vegetable-rich' dietary pattern have been shown

Table 2. Food and nutrient intakes across quartiles $(Q)$ of the dietary patterns at baseline in Chinese adults

(Mean values and their standard errors or percentages, $n$ 1231)*

\begin{tabular}{|c|c|c|c|c|c|c|c|c|c|}
\hline & \multicolumn{9}{|c|}{ Intake of dietary pattern quartiles } \\
\hline & \multicolumn{2}{|c|}{ Q1 } & \multicolumn{2}{|c|}{ Q2 } & \multicolumn{2}{|c|}{ Q3 } & \multicolumn{2}{|c|}{ Q4 } & \multirow[b]{2}{*}{$P$ for treno } \\
\hline & Mean & SE & Mean & SE & Mean & SE & Mean & SE & \\
\hline \multicolumn{10}{|l|}{ 'Traditional' dietary pattern } \\
\hline Fresh vegetables $(\mathrm{g} / \mathrm{d})$ & 177 & 8 & 225 & 8 & 272 & 8 & 365 & 8 & $<0.001$ \\
\hline Fruits $(\mathrm{g} / \mathrm{d})$ & 58 & 5 & 44 & 5 & 45 & 5 & 80 & 5 & $<0.001$ \\
\hline Rice $(g / d)$ & 123 & 6 & 299 & 6 & 382 & 6 & 478 & 6 & $<0.001$ \\
\hline Wheat flour ( $g / d$ ) & 298 & 6 & 40 & 6 & 20 & 6 & 21 & 6 & $<0.001$ \\
\hline Whole grains $(g / d)$ & 15 & 1 & 5 & 1 & 2 & 1 & 3 & 1 & $<0.001$ \\
\hline Root vegetables (g/d) & 21 & 1 & 10 & 1 & 10 & 1 & 9 & 1 & $<0.001$ \\
\hline Pickled vegetables $(\mathrm{g} / \mathrm{d})$ & 18 & 2 & 14 & 2 & 16 & 2 & 26 & 2 & $<0.001$ \\
\hline Pork $(\mathrm{g} / \mathrm{d})$ & 21 & 2 & 33 & 2 & 43 & 2 & 59 & 2 & $<0.001$ \\
\hline Fish $(\mathrm{g} / \mathrm{d})$ & 24 & 2 & 28 & 2 & 30 & 2 & 35 & 2 & $<0.001$ \\
\hline Energy density $(\mathrm{kJ} / \mathrm{g}) \dagger$ & 8.7 & 0.1 & 7.9 & 0.1 & 8.1 & 0.1 & 7.9 & 0.1 & $<0.001$ \\
\hline Energy $(\mathrm{kJ} / \mathrm{d})$ & 10002 & 142 & 9126 & 142 & 9750 & 142 & 10207 & 142 & $<0.001$ \\
\hline Protein $(\mathrm{g} / \mathrm{d})$ & 72 & 1 & 69 & 1 & 74 & 1 & 75 & 1 & $<0.001$ \\
\hline Carbohydrate $(\mathrm{g} / \mathrm{d})$ & 345 & 5 & 283 & 5 & 308 & 5 & 332 & 5 & $<0.001$ \\
\hline Fat $(g / d)$ & 75 & 2 & 80 & 0 & 85 & 2 & 87 & 2 & $<0.001$ \\
\hline Fat energy (\%) & 28 & 1 & 33 & 1 & 33 & 1 & 32 & 1 & $<0.001$ \\
\hline Fat energy $>30 \%(\%)$ & 40 & 3 & 64 & 3 & 63 & 3 & 58 & 3 & $<0.001$ \\
\hline \multicolumn{10}{|l|}{ Fat distribution (\%) } \\
\hline Plant foods & 77.5 & $1 \cdot 2$ & $60 \cdot 4$ & $1 \cdot 2$ & $61 \cdot 3$ & $1 \cdot 2$ & 61.5 & $1 \cdot 2$ & $<0.001$ \\
\hline Animal foods & 22.5 & 0.9 & 39.9 & 0.9 & 39.0 & 0.9 & 37.9 & 0.9 & $<0.001$ \\
\hline Vegetable oil $(\mathrm{g} / \mathrm{d})$ & 42 & 2 & 39 & 2 & 40 & 2 & 43 & 2 & 0.184 \\
\hline Fibre $(g / d)$ & $18 \cdot 7$ & 0.5 & 8.4 & 0.5 & $9 \cdot 3$ & 0.5 & 9.9 & 0.5 & $<0.001$ \\
\hline Age (years) & 47.9 & 0.7 & 50.8 & 0.8 & 48.4 & 0.8 & 48.8 & 0.7 & 0.036 \\
\hline Men (\%) & \multicolumn{2}{|c|}{41.2} & \multicolumn{2}{|c|}{$32 \cdot 1$} & \multicolumn{2}{|c|}{$42 \cdot 2$} & \multicolumn{2}{|c|}{50.2} & $<0.001$ \\
\hline Low education (\%) & \multicolumn{2}{|c|}{$60 \cdot 1$} & \multicolumn{2}{|c|}{$53 \cdot 6$} & \multicolumn{2}{|c|}{$51 \cdot 6$} & \multicolumn{2}{|c|}{47.6} & 0.026 \\
\hline Manual job (\%) & \multicolumn{2}{|c|}{$57 \cdot 1$} & & & & & & & 0.002 \\
\hline Active commuting $\neq(\%)$ & & & & & & & & & \\
\hline None & & & & & & & & & \\
\hline $1-30 \mathrm{~min} / \mathrm{d}$ & & & & & & & & & $<0.001$ \\
\hline$>30 \mathrm{~min} / \mathrm{d}$ & & & & & & & & & \\
\hline Leisure-time physical act & (\%) & & & & & & & & \\
\hline None & & & & & & & & & \\
\hline $1-30 \mathrm{~min} / \mathrm{d}$ & & & & & & & & & 0.543 \\
\hline$>30 \mathrm{~min} / \mathrm{d}$ & & & & & & & & & \\
\hline Smoker (\%) & & & & & & & & & 0.104 \\
\hline Alcohol drinker (\%) & & & & & & & & & 0.788 \\
\hline 'Macho' pattern & & & & & & & & & \\
\hline Age (years) & 52.5 & 0.8 & $49 \cdot 1$ & 0.7 & $47 \cdot 7$ & 0.8 & $46 \cdot 7$ & 0.7 & $<0.001$ \\
\hline Men (\%) & & & & & & & & & $<0.001$ \\
\hline Low education (\%) & & & & & & & & & $<0.001$ \\
\hline Energy intake $(\mathrm{kJ} / \mathrm{d})$ & 10031 & 147 & 9570 & 142 & 9536 & 142 & 9951 & 147 & 0.024 \\
\hline 'Sweet tooth' pattern & & & & & & & & & \\
\hline Age (years) & 48.6 & 0.7 & 50.7 & 0.7 & $49 \cdot 8$ & 0.8 & 46.9 & 0.8 & 0.002 \\
\hline Men (\%) & & & & & & & & & $<0.001$ \\
\hline Low education (\%) & & & & & & & & & $<0.001$ \\
\hline Energy intake $(\mathrm{kJ} / \mathrm{d})$ & 10655 & 142 & 9863 & 142 & 9515 & 142 & 9055 & 142 & $<0.001$ \\
\hline 'Vegetable-rich' pattern & & & & & & & & & \\
\hline Age (years) & 49.5 & 0.7 & 48.2 & 0.7 & 49.4 & 0.8 & 48.9 & 0.7 & 0.570 \\
\hline Men (\%) & & & & & & & & & 0.006 \\
\hline Low education (\%) & & & & & & & & & 0.016 \\
\hline Energy intake $(\mathrm{kJ} / \mathrm{d})$ & 9633 & 142 & 9524 & 142 & 9775 & 142 & 10157 & 142 & 0.012 \\
\hline
\end{tabular}

${ }^{*}$ All values of food and nutrient intakes are adjusted for age.

† Calculated from food only (excludes beverages) based on the FFQ.

$\ddagger$ Active commuting including walking and cycling. 
elsewhere ${ }^{(10)}$. Across quartiles of the 'vegetable-rich' pattern, the intake of energy, wheat flour and vegetable oil increased. There was a significant inverse association between the 'sweet tooth' pattern and energy intake. Men were more likely to have a high intake of the 'macho' pattern but less likely to have a high 'sweet tooth' pattern.

Fig. 1 shows the mean 5-year weight change according to quartiles of the dietary patterns. After adjustment for age, sex and baseline weight, the 'traditional' dietary pattern was inversely associated with weight gain, while the 'vegetable-rich' pattern was positively associated with weight gain. The mean 5-year weight gain among all participants was $0.8(\mathrm{SD} 4.7) \mathrm{kg}$. The mean weight changes across quartiles of the 'traditional' pattern were $2 \cdot 0,0 \cdot 6,0.6$ and $0.0 \mathrm{~kg}$ ( $P$ for trend $<0.001)$. The corresponding values were $0.4,0.5,0.7$ and $1.6 \mathrm{~kg}$ across quartiles of the 'vegetable-rich' pattern ( $P$ for trend $=0.004)$. No significant associations of the 'macho' and 'sweet tooth' patterns with weight gain were found. There was no U-shaped association between the 'sweet tooth' pattern and weight gain when we put the square term of the 'sweet tooth' score as a continuous variable in the regression model (data not shown). As there was a large difference in the intake of wheat flour across quartiles of the 'traditional dietary pattern', we stratified the analysis by low and high intakes of wheat flour. A similar association between the 'traditional' pattern and weight gain was found. The line for low wheat flour intake sloped less than the unstratified curve for the 'traditional' pattern shown in Fig. 1 (data not shown).

In multivariate linear regression (Table 3), using the first quartile as the reference, participants in the highest quartile
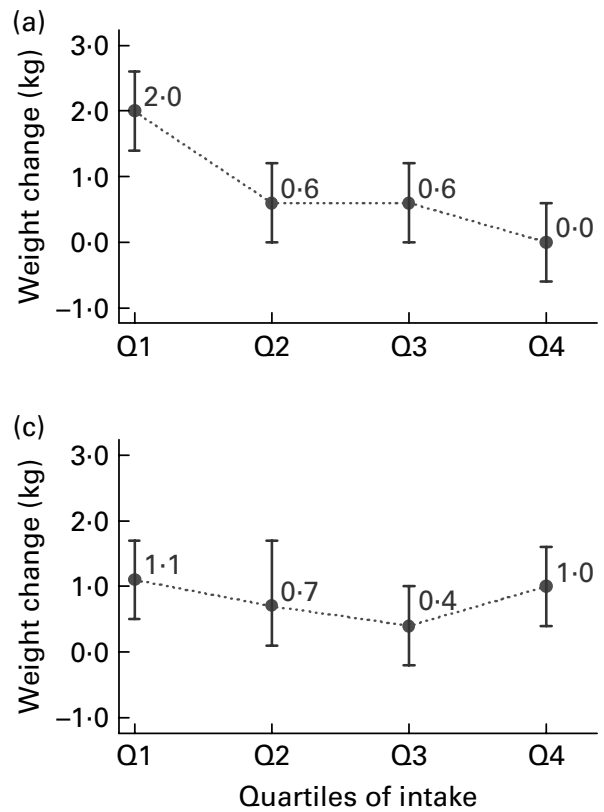

of the 'traditional' dietary pattern had a $\beta$ of $-2 \cdot 18(95 \% \mathrm{CI}$ $-2.91,-1.45)$ for weight gain. However, the $\beta$ for weight change of the highest quartile of the 'vegetable-rich' pattern was 1.00 (95\% CI $0.25,1.74)$. Mutually adjusting for the other dietary patterns did not change the results (data not shown).

In the stratified multivariate analyses (Table 4), an inverse association between the 'traditional' dietary pattern and weight gain was present in subjects aged $<40$ years and $\geq 40$ years, in non-smokers and smokers, in overweight and normal-weight subjects, in alcohol drinkers and non-drinkers, and in men and women. There were no significant interactions between any of the above factors and the 'traditional' dietary pattern with weight gain. Among the overweight subjects at baseline, those who had the highest intake of the 'traditional' pattern had the lowest weight gain: compared with the first quartile, the fourth quartile had a $\beta$ of -2.63 (95\% CI $-3.94,-1.32$ ) for weight gain. Physical activity did not modify the association.

\section{Discussion}

The rice-rich 'traditional' dietary pattern was inversely associated with weight gain among adults in China in a 5-year follow-up in the Jiangsu Nutrition and Health Study. The opposite relationship was found in regard to the 'vegetablerich' dietary pattern. The association between weight loss and the 'traditional' pattern across quartile intakes seemed to be stronger among overweight subjects than normal-weight subjects. This association was not modified by age, sex, BMI, smoking, alcohol drinking and other dietary patterns. (b)

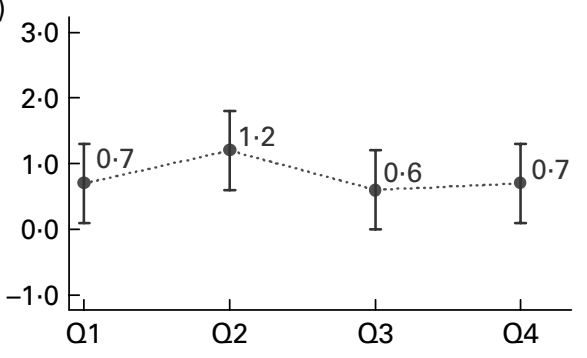

(d)

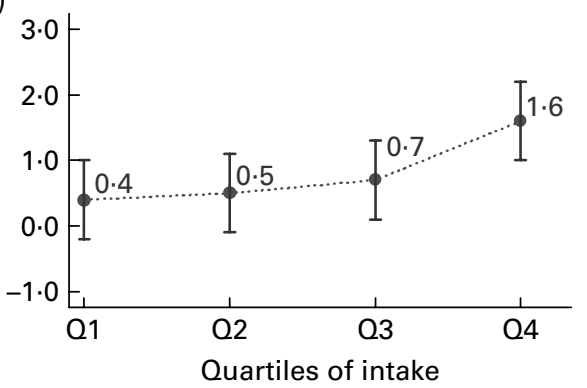

Fig. 1. Mean 5-year weight change $(95 \% \mathrm{Cl})$ according to quartiles $(\mathrm{Q} 1-\mathrm{Q} 4)$ of the dietary patterns. Means were adjusted for age, sex and baseline weight. (a) Traditional dietary pattern $(P<0.001)$, (b) macho dietary pattern $(P=0.300)$, (c) sweet tooth dietary pattern $(P=0.164)$ and (d) vegetable-rich dietary pattern $(P=0.004)$. 
Table 3. Linear regression $\beta$ coefficients $(95 \% \mathrm{Cl}$ ) for quartiles (Q1-Q4) of the four dietary patterns predicting 5 -year change in weight in 1231 adults participating in the Jiangsu Health Cohort study†

( $\beta$ Coefficients and $95 \%$ confidence intervals)

\begin{tabular}{|c|c|c|c|c|c|c|c|c|}
\hline & \multicolumn{8}{|c|}{5 -Year change in wt $(\mathrm{kg})$} \\
\hline & \multirow{2}{*}{$\begin{array}{l}\text { Q1 ( } n \text { 308) } \\
\text { Reference }\end{array}$} & \multicolumn{2}{|c|}{ Q2 (n 308) } & \multicolumn{2}{|c|}{ Q3 (n 308) } & \multicolumn{2}{|c|}{ Q4 (n 307) } & \multirow[b]{2}{*}{$P$ for treno } \\
\hline & & $\beta$ & $95 \% \mathrm{Cl}$ & $\beta$ & $95 \% \mathrm{Cl}$ & $\beta$ & $95 \% \mathrm{Cl}$ & \\
\hline \multicolumn{9}{|l|}{ Macho pattern } \\
\hline $\begin{array}{l}\text { Adjusted for age and } \\
\text { sex (model } 1)\end{array}$ & 0 & 0.49 & $-0 \cdot 23,1 \cdot 22$ & -0.14 & $-0.87,0.60$ & -0.08 & $-0.85,0.69$ & 0.474 \\
\hline $\begin{array}{l}\text { Multivariate adjusted } \\
\text { (model 2) }\end{array}$ & 0 & 0.59 & $-0.14,1.33$ & -0.04 & $-0.79,0.71$ & -0.13 & $-0.96,0.69$ & 0.434 \\
\hline $\begin{array}{l}\text { Multivariate adjusted }+ \\
\text { energy (model 3) }\end{array}$ & 0 & 0.59 & $-0.15,1.32$ & -0.05 & $-0.80,0.70$ & -0.12 & $-0.95,0.70$ & 0.439 \\
\hline \multicolumn{9}{|l|}{ Traditional pattern } \\
\hline $\begin{array}{l}\text { Adjusted for age and } \\
\text { sex (model 1) }\end{array}$ & 0 & $-1.46^{\star}$ & $-2.17,-0.75$ & $-1.45^{\star}$ & $-2 \cdot 16,-0.75$ & $-2 \cdot 05^{\star}$ & $-2 \cdot 76,-1.34$ & $<0.001$ \\
\hline $\begin{array}{l}\text { Multivariate adjusted } \\
\quad \text { (model 2) }\end{array}$ & 0 & $-1.56^{\star}$ & $-2 \cdot 30,-0.83$ & $-1 \cdot 45^{*}$ & $-2 \cdot 17,-0.72$ & $-2 \cdot 10^{\star}$ & $-2 \cdot 83,-1 \cdot 37$ & $<0.001$ \\
\hline $\begin{array}{l}\text { Multivariate adjusted }+ \\
\text { energy (model } 3 \text { ) }\end{array}$ & 0 & $-1.53^{\star}$ & $-2 \cdot 27,-0.80$ & $-1.47^{*}$ & $-2 \cdot 20,-0.75$ & $-2 \cdot 18^{\star}$ & $-2 \cdot 91,-1.45$ & $<0.001$ \\
\hline \multicolumn{9}{|l|}{ Sweet tooth pattern } \\
\hline $\begin{array}{l}\text { Adjusted for age and } \\
\text { sex (model 1) }\end{array}$ & 0 & -0.42 & $-1 \cdot 15,0 \cdot 30$ & -0.77 & $-1.50,-0.04$ & -0.13 & $-0.86,0.60$ & 0.548 \\
\hline $\begin{array}{l}\text { Multivariate adjusted } \\
\text { (model 2) }\end{array}$ & 0 & -0.40 & $-1 \cdot 16,0.35$ & -0.57 & $-1 \cdot 34,0 \cdot 21$ & -0.09 & $-0.88,0.70$ & 0.802 \\
\hline $\begin{array}{l}\text { Multivariate adjusted }+ \\
\text { energy (model } 3 \text { ) }\end{array}$ & 0 & -0.38 & $-1 \cdot 13,0.38$ & -0.52 & $-1 \cdot 29,0 \cdot 26$ & -0.03 & $-0.83,0.77$ & 0.93 \\
\hline \multicolumn{9}{|l|}{ Vegetable-rich pattern } \\
\hline $\begin{array}{l}\text { Adjusted for age and } \\
\text { sex (model } 1)\end{array}$ & 0 & 0.00 & $-0.71,0.72$ & 0.26 & $-0.46,0.97$ & $1 \cdot 15^{\star}$ & $0.44,1.87$ & 0.001 \\
\hline $\begin{array}{l}\text { Multivariate adjusted } \\
\quad \text { (model 2) }\end{array}$ & 0 & -0.04 & $-0.75,0.68$ & 0.35 & $-0.37,1.08$ & $1.03^{*}$ & $0 \cdot 28,1 \cdot 77$ & 0.004 \\
\hline $\begin{array}{l}\text { Multivariate adjusted }+ \\
\text { energy (model 3) }\end{array}$ & 0 & -0.05 & $-0.77,0.67$ & 0.32 & $-0.41,1.04$ & $1 \cdot 00^{*}$ & $0 \cdot 25,1 \cdot 74$ & 0.005 \\
\hline
\end{tabular}

*** $P<0.01$.

† All the models were adjusted for baseline weight. Multivariate model adjusted for variables in model 1 and smoking (yes/no), drinking (yes/no), active commuting (no, 1-30 and $>30 \mathrm{~min} / \mathrm{d}$ ), leisure-time physical activity (no, 1-30 and $>30 \mathrm{~min} / \mathrm{d}$ ), education (low, medium and high) and occupation (manual/non-manual).

A large difference in the intake of rice and wheat flour was found across quartiles of the 'traditional' dietary pattern. It represented two different sub-patterns with two different staple foods in inverse proportions, i.e. rice and wheat. Rice is a low-energy food that contributes to the bulk of the traditional diet. Compared with wheat, rice absorbs more water when cooked. In addition, different cooking methods are used in preparing these two staple foods. For instance, steamed rice contains twice the amount of water and half of the energy compared with steamed bread ${ }^{(17)}$. Thus, the energy density of the rice staple diet is usually lower than the one based on wheat. Since the content of wheat was only predominant in the first quartile of this dietary pattern, this may partly explain the negative association between the 'traditional' pattern and weight gain in the present study. It is known that high energy density of the diet is related to obesity ${ }^{(19,20)}$. Another possible explanation of the negative relationship between the 'traditional' pattern and weight gain could be the intake of vegetables. The intake of fresh vegetables in the fourth quartile of the 'traditional' pattern was twice that of the first quartile. A usual cooking method for vegetables in the study area is stir-frying with vegetable oil, which would increase energy density.
Intake of fried foods is found to increase the risk of obesity $^{(10,21)}$. However, the present findings revealed no significant differences in vegetable oil intake across quartiles of the 'traditional' pattern, indicating alternative ways of cooking, regardless of intake of vegetables. Thus, this pattern may help to prevent weight gain even if the mean energy intake from fat is high. In fact, stirfrying is usually used to cook wheat-based staple foods in the area, while steam or water, rather than oil, is used for the cooking of rice-based foods.

The difference in energy intake across quartiles in the 'traditional' dietary pattern was rather small, implying that this difference cannot explain the relationship with weight gain. Also, this association could not be explained by fat intake, since a higher intake of the 'traditional' pattern was associated with a higher intake of fat. Intake of fibre was the highest among people in the first quartile of the 'traditional' pattern. Thus, the benefit of weight maintenance of the traditional dietary pattern was not related to dietary fibre.

Our finding is consistent with a study from Brazil, which showed that a traditional dietary pattern with a high intake of rice was related to a lower risk of obesity ${ }^{(22)}$. It is also consistent with a study in China, which showed that 
Table 4. Stratified regression coefficients $(95 \% \mathrm{Cl})$ for weight change according to the intake of 'traditional' dietary pattern quartiles ( $\beta$ Coefficients and $95 \%$ confidence intervals)

\begin{tabular}{|c|c|c|c|c|c|c|c|c|}
\hline & \multicolumn{8}{|c|}{ Quartiles of the 'traditional' dietary pattern } \\
\hline & \multirow{2}{*}{$\begin{array}{l}\text { Q1 } \\
\text { Reference }\end{array}$} & \multicolumn{2}{|r|}{ Q2 } & \multicolumn{2}{|r|}{ Q3 } & \multicolumn{2}{|r|}{ Q4 } & \multirow[b]{2}{*}{$P$ for trend } \\
\hline & & $\beta$ & $95 \% \mathrm{Cl}$ & $\beta$ & $95 \% \mathrm{Cl}$ & $\beta$ & $95 \% \mathrm{Cl}$ & \\
\hline \multicolumn{9}{|l|}{$\mathrm{BMI}\left(\mathrm{kg} / \mathrm{m}^{2}\right)$} \\
\hline$\geq 24(n 487)$ & 0 & -0.99 & $-2.35,0.38$ & -1.92 & $-3.22,-0.62$ & -2.63 & $-3.94,-1.32$ & $<0.001$ \\
\hline$<24(n 744)$ & 0 & -1.70 & $-2.56,-0.83$ & -1.27 & $-2.12,-0.41$ & -1.87 & $-2.74,-0.99$ & $<0.001$ \\
\hline \multicolumn{9}{|l|}{ Smoking } \\
\hline Non-smokers ( $n$ 897) & 0 & -1.91 & $-2.74,-1.08$ & $-1 \cdot 71$ & $-2.52,-0.90$ & $-2 \cdot 28$ & $-3.11,-1.44$ & $<0.001$ \\
\hline Smokers $(n$ 334) & 0 & -0.51 & $-2 \cdot 16,1 \cdot 13$ & -0.75 & $-2.40,0.91$ & -1.78 & $-3.35,-0.20$ & 0.025 \\
\hline \multicolumn{9}{|l|}{ Alcohol drinking } \\
\hline Yes $(n 306)$ & 0 & -0.66 & $-2.24,0.92$ & -0.63 & $-2 \cdot 17,0.92$ & -1.62 & $-3.13,-0.12$ & 0.045 \\
\hline No $(n 925)$ & 0 & -1.92 & $-2 \cdot 77,-1.07$ & $-1 \cdot 77$ & $-2.60,-0.93$ & $-2 \cdot 32$ & $-3.17,-1.47$ & $<0.001$ \\
\hline \multicolumn{9}{|l|}{ Sexes } \\
\hline Men $(n 510)$ & 0 & -0.77 & $-2 \cdot 17,0.64$ & $-1 \cdot 26$ & $-2.57,0.04$ & $-2 \cdot 32$ & $-3.59,-1.05$ & $<0.001$ \\
\hline Women $(n 721)$ & 0 & -2.09 & $-2.94,-1.23$ & -1.69 & $-2.56,-0.83$ & -2.04 & $-2.95,-1.14$ & $<0.001$ \\
\hline \multicolumn{9}{|l|}{ Age (years) } \\
\hline$<40(n 321)$ & 0 & -0.92 & $-2.41,0.57$ & $-2 \cdot 12$ & $-3.51,-0.73$ & $-2 \cdot 29$ & $-3.75,-0.82$ & 0.001 \\
\hline$\geq 40(n 910)$ & 0 & -1.58 & $-2.45,-0.71$ & $-1 \cdot 13$ & $-2.00,-0.25$ & -2.00 & $-2 \cdot 86,-1 \cdot 14$ & $<0.001$ \\
\hline \multicolumn{9}{|l|}{ Job } \\
\hline Manual ( $n$ 639) & 0 & -1.66 & $-2 \cdot 70,-0.62$ & -2.06 & $-3.04,-1.07$ & -2.50 & $-3.47,-1.53$ & $<0.001$ \\
\hline Non-manual ( $n$ 592) & 0 & -1.36 & $-2.43,-0.29$ & -0.87 & $-1.96,0.22$ & -1.68 & $-2.82,-0.53$ & 0.017 \\
\hline
\end{tabular}

* Adjusted for variables of the multivariate model (model 3) in Table 3. Stratification variables were based on baseline information.

people having the rice- and vegetable-rich 'Green Water' food cluster had a lower prevalence of overweight/obesity compared with the wheat-rich 'Yellow Earth' food cluster $(18 v .27 \%)^{(23)}$. However, a positive association between the rice-based dietary pattern and BMI was reported in Japanese $^{(8)}$ and in Hispanic elders ${ }^{(24)}$. Further research is needed to unravel the mechanisms behind this association.

The present study showed that the association between weight loss during the 5 years of follow-up and the traditional dietary pattern seemed to be stronger among overweight subjects than among normal-weight subjects. Whether this finding can be generalised as a way to prevent weight gain in other populations is of interest.

A positive association between the 'vegetable-rich' dietary pattern and weight gain was found in the present study. It confirms our previous cross-sectional findings of a relationship between a vegetable-rich dietary pattern and obesity ${ }^{(10)}$. We hypothesised that this association could be linked to vegetable oil intake increasing across quartiles of the 'vegetable-rich' pattern ${ }^{(10)}$. In addition, this may also be explained by the difference in the intake of rice and wheat flour across quartiles of the "vegetable-rich' pattern, which was opposite to that of the 'traditional' pattern ${ }^{(10)}$, implying a higher intake of wheat in the highest quartile of the 'vegetable-rich' pattern. Further research is needed to understand the association. The food items included in this dietary pattern are recommended by the Chinese Nutrition Society. Thus, the finding has public health significance.

The limitation of the study is the high rate of those lost to follow-up due to migration and city construction. The rapid economic development in the province has caused a large proportion of rural inhabitants to move to the city in search of jobs. At the same time, some people have moved out of the city during the past 10 years due to a high percentage of old houses that have been demolished in order to build new buildings or roads. However, there was no significant difference in the mean BMI between those lost to follow-up and those retained, and thus unlikely to bias the association between dietary pattern and weight change. The second limitation of the study is the use of self-reported physical activities. However, this measurement has been previously validated and found satisfactory. Using posterior approaches to defining dietary patterns has its limitation. The defined dietary patterns are strongly affected by subjective analytic decisions, which are common in all factor analyses. The FFQ was validated at the national level, but the validation study did include samples from the study area. Furthermore, the possible change in dietary habits was not analysed in the present paper. However, it is assumed that the FFQ based on the previous year's dietary habits is a good proxy for dietary habits during the 5-year period, since dietary habits have been found to be reasonably stable through the life course ${ }^{(25)}$. For the same reason, the use of $3 \mathrm{~d}$ individual food records was necessary to estimate total energy in order to be able to adjust for this variable in the analysis of independent association between dietary pattern and weight change. It has been shown earlier that there is a good correlation between the FFQ and the $3 \mathrm{~d}$ food record $^{(15,16)}$. The strength of the study is that it covered participants using both rice and wheat flour as staple foods. It was different from the Shanghai Men's Study, where the majority of the participants were using rice as 
their staple food ${ }^{(9)}$. The strength of the present study is that weight was measured by health workers; thus underreporting of weight was not a problem. Stratified analyses showed consistent results.

In conclusion, the 'traditional' dietary pattern was negatively associated with weight gain and the 'vegetablerich' pattern was positively associated with weight gain in Chinese adults. More research is needed to reveal the mechanisms involved in explaining these associations.

\section{Acknowledgements}

Z. S. had full access to all the data in the study and took responsibility for the integrity of the data and the accuracy of the data analysis. Z. S. drafted the manuscript. B. Y., Y. D. and H. Z. were responsible for data collection. All the authors gave critical review of the manuscript. The study was funded by the Jiangsu Provincial Natural Science Foundation BK2008464 and the Jiangsu Provincial Health Bureau, China. The authors thank the participating Regional Centers for Disease Control and Prevention in Jiangsu Province, including the Nanjing, Xuzhou, Jiangyin, Taicang, Suining, Jurong, Sihong and Haimen Centers for their support for data collection. The authors have no relevant financial interest in the present article.

\section{References}

1. World Health Organization (2000) Obesity: Prevention and Managing the Global Epidemic. WHO Technical Report Series no. 894. Geneva: World Health Organization.

2. WHO/FAO (2003) Diet, Nutrition and the Prevention of Chronic Diseases: Report of a Joint WHO/FAO Expert Consultation. Geneva: World Health Organization.

3. Hu FB (2008) Obesity Epidemiology. New York: Oxford University Press.

4. Newby PK \& Tucker KL (2004) Empirically derived eating patterns using factor or cluster analysis: a review. Nutr Rev 62, $177-203$.

5. Newby PK, Muller D, Hallfrisch J, et al. (2004) Food patterns measured by factor analysis and anthropometric changes in adults. Am J Clin Nutr 80, 504-513.

6. Newby PK, Weismayer C, Akesson A, et al. (2006) Longitudinal changes in food patterns predict changes in weight and body mass index and the effects are greatest in obese women. J Nutr 136, 2580-2587.

7. Togo P, Osler M, Sorensen TI, et al. (2004) A longitudinal study of food intake patterns and obesity in adult Danish men and women. Int J Obes Relat Metab Disord 28, 583-593.
8. Okubo H, Sasaki S, Murakami K, et al. (2008) Three major dietary patterns are all independently related to the risk of obesity among 3760 Japanese women aged 18-20 years. Int J Obes (Lond) 32, 541-549.

9. Cai H, Zheng W, Xiang YB, et al. (2007) Dietary patterns and their correlates among middle-aged and elderly Chinese men: a report from the Shanghai Men's Health Study. Br J Nutr 98, 1006-1013.

10. Shi Z, Hu X, Yuan B, et al. (2008) Vegetable rich food pattern is related to obesity in China. Int J Obes (Lond) 32, 975-984.

11. Shai I, Schwarzfuchs D, Henkin Y, et al. (2008) Weight loss with a low-carbohydrate, Mediterranean, or low-fat diet. $N$ Engl J Med 359, 229-241.

12. Sacks FM, Bray GA, Carey VJ, et al. (2009) Comparison of weight-loss diets with different compositions of fat, protein, and carbohydrates. $N$ Engl J Med 360, 859-873.

13. Woo J, Woo KS, Leung SS, et al. (2001) The Mediterranean score of dietary habits in Chinese populations in four different geographical areas. Eur J Clin Nutr 55, 215-220.

14. Chen CM, Zhao W, Yang Z, et al. (2008) The role of dietary factors in chronic disease control in China. Obes Rev 9, Suppl. 1, 100-103.

15. Zhao W, Hasegawa K \& Chen J (2002) The use of foodfrequency questionnaires for various purposes in China. Public Health Nutr 5, 829-833.

16. Li YP, He YN, Zhai FY, et al. (2006) Comparison of assessment of food intakes by using 3 dietary survey methods. Zhonghua Yu Fang Yi Xue Za Zhi 40, 273-280.

17. Yang Y (2005) Chinese Food Composition Table 2004. Beijing: Peking University Medical Press.

18. Ma G, Luan D, Liu A, et al. (2007) The analysis and evaluation of a physical activity questionnaire of Chinese employed population. Ying Yang Xue Bao 29, 217-221.

19. Prentice AM \& Jebb SA (2003) Fast foods, energy density and obesity: a possible mechanistic link. Obes Rev 4, 187-194.

20. Savage JS, Marini M \& Birch LL (2008) Dietary energy density predicts women's weight change over 6y. Am J Clin Nutr 88, 677-684.

21. Guallar-Castillon P, Rodriguez-Artalejo F, Fornes NS, et al. (2007) Intake of fried foods is associated with obesity in the cohort of Spanish adults from the European Prospective Investigation into Cancer and Nutrition. Am J Clin Nutr 86, $198-205$.

22. Sichieri R (2002) Dietary patterns and their associations with obesity in the Brazilian city of Rio de Janeiro. Obes Res 10, 42-48.

23. Zhang X, Dagevos H, He Y, et al. (2008) Consumption and corpulence in China: a consumer segmentation study based on the food perspective. Food Policy 33, 37-47.

24. Lin H, Bermudez OI \& Tucker KL (2003) Dietary patterns of Hispanic elders are associated with acculturation and obesity. J Nutr 133, 3651-3657.

25. Borland SE, Robinson SM, Crozier SR, et al. (2007) Stability of dietary patterns in young women over a 2-year period. Eur J Clin Nutr 62, 119-126. 